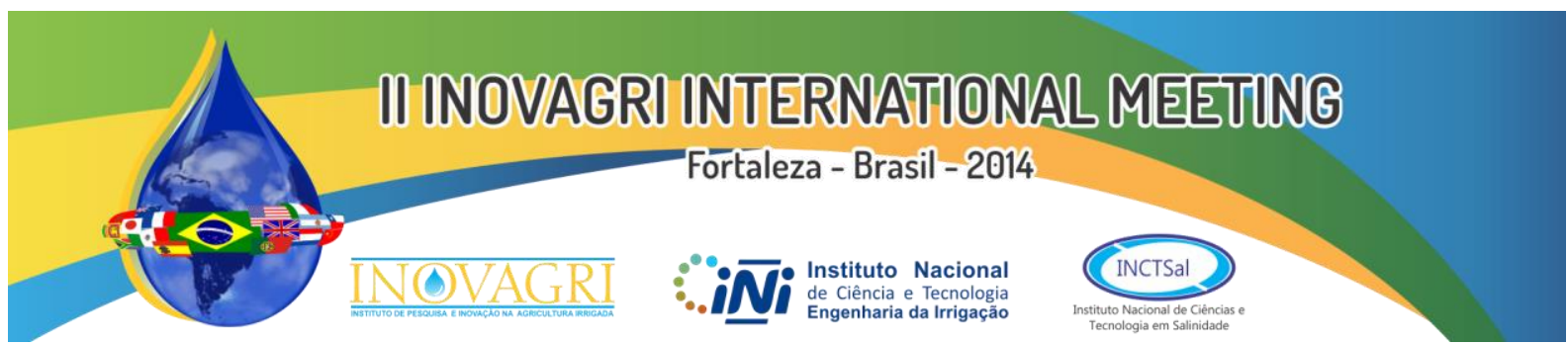

http://dx.doi.org/10.12702/ii.inovagri.2014-a713

\title{
DESEMPENHO DE EMISSORES DE BAIXO CUSTO PARA USO EM IRRIGAÇÃO LOCALIZADA
}

\author{
F. P. Santos ${ }^{1}$, J. C. Texeira ${ }^{1}$, E. F. Coelho ${ }^{2}$, R. C. Oliveira ${ }^{1}$, R. T. M. Araújo ${ }^{1}$
}

\begin{abstract}
RESUMO: Os emissores usados na irrigação localizada até pouco tempo eram usados para atender a sistemas de maior custo. Atualmente existem emissores de custo pelo menos $50 \%$ menor que os encontrados no mercado. A falta de informações do desempenho desses emissores deixa os produtores sem indicadores para avaliar o produto. $\mathrm{O}$ trabalho teve como objetivo avaliar o desempenho de emissores de baixo custo por meio da variação de vazão e de pressão entre o primeiro e ultimo emissor da linha lateral. Usou-se um delineamento experimental inteiramente casualizados em esquema de parcelas subdivididas, com o tipo de emissor na parcela (gotejador autocompensante, gotejador perfurado, de vazão regulável, gotejador difusor de orifício fixo, gotejador ajustável de vazão regulável com regulagem de um giro do emissor e com dois giros do emissor) e pressão de serviço na subparcela $(30,60,90$ e $120 \mathrm{kPa})$. A pressão de $30 \mathrm{kPa}$ foi a que resultou em maior variação de vazão e pressão e a de $120 \mathrm{kPa}$ a que resultou em menor variação. O emissor perfurado de vazão regulável foi o que apresentou as maiores variações de vazão independente das pressões de serviço e o gotejador autocompensante o que resultou em menores variações de vazão para pressões acima de $30 \mathrm{kPa}$. As variações de pressão na linha lateral foram menores para o gotejador autocompensante e para o gotejador ajustável de vazão regulável em relação aos demais.
\end{abstract}

PALAVRAS CHAVE: Gotejamento, difusores, variação de vazão

\section{PERFORMANCE OF LOW COST EMITTERS FOR USING IN TRICKLE IRRIGATION}

ABSTRACT: The emitters used in trickle irrigation in the past were for high cost systems. Nowadays, there are emitters of cost $50 \%$ less expensive than the ones commonly found in marketplace. The lack of information about low cost emitters limitates farmers for buying these products due to absence of indicators for product evaluation. This work had as objective to evaluate the performance of low cost emitters by means of data of pressure and flow rate variation between the first and the last emitter in the lateral line. A completely randomized design with three repetitions in split plot was used. The plot corresponded to the kind of emitter (auto compensating dripper, drilled dripper with adjustable flow rate, diffuser dripper of fixed orifice, adjustable flow rate dripper with one spin and two spins of the diffuser). The work pressure was in the split plot $(30,60,90$ and $120 \mathrm{kPa})$. The $30 \mathrm{kPa}$ pressure was the one that resulted in larger flow rate and pressure variation and the $120 \mathrm{kPa}$ work pressure was the one of smaller flow rate and pressure variation. The drilled emitter was the one that showed the larger flow rate variations no matter the work pressure and the auto compensating dripper was the one of smaller flow rate variation for pressures above $30 \mathrm{kPa}$. Pressure variation in the lateral line was smaller when using the auto compensating dripper and the adjustable flow rate dripper with one spin and two spins of the diffuser.

KEY WORDS: drip irrigation, diffusers, flow rate variation

\section{INTRODUÇÃO}

Os materiais de irrigação mais utilizados tem sido voltados a projetos de médio e grande porte em irrigação; consequentemente, os projetos de pequeno porte tem utilizado os mesmos materiais, sendo

\footnotetext{
${ }^{1}$ Estudante de Agronomia,Graduando, UFRB/Cruz das Almas - BA, Fone: (075)92313625, fpsagro@ gmail.com 2 Eng $^{\circ}$ Agricola, Pesquisador..,Embrapa Mandioca e Fruticultura(CNPMF)/Cruz das Almas - BA
} 
os custos iniciais de instalação de sistemas de irrigação industriais relevantes para o pequeno produtor em geral particularmente no que tange emissores de água de irrigação. Normalmente esses emissores são vendidos a preços que, apesar da variação de região ou território, entre 50 centavos a 1,50 centavos para gotejadores e podendo chegar a 4,00 reais para microaspersores, variando o custo de instalação entre 3000 a 6000 reais (MAROUELLI; SIVA, 2000).

$\mathrm{Na}$ agricultura familiar de baixa renda, qualquer redução de preço é bem vinda ao agricultor. Várias recomendações de sistemas para pequena agricultura estão disponíveis, entre estes pode-se citar as de Daniel Hillel (http://www.fao. org/NEWS/1 997/970704-e.htm) que são basicamente o uso de irrigação por potes, irrigação tipo xique-xique, borbulhador de pequena carga hidráulica (low-head bubbler) e algumas adaptações como uso de garrafas pets perfuradas em lugar de potes dentro do solo. No Nordeste brasileiro tem sido encontrado vários sistemas de irrigação concebidos para agricultura familiar de baixa renda, tais como a irrigação por potes, o xique-xique, borbulhador de pequena carga hidráulica (bubbler), além de outros. O mercado tem disponibilizado também emissores (gotejador e difusor), de baixo custo, de vazão regulável, que a principio, pode ser usado pelos agricultores irrigantes. Coelho et al. (2012) avaliou alguns desses sistemas em condições de campo (gotejador e microaspersor artesanal, além de um gotejador de vazão regulavel) e verificou que, a limitação de emissores de baixo custo refere-se a uniformidade de distribuição de água, que normalmente é menor para esses materiais quando instalados em campo, no entanto sem efeito negativo relevante na produção final das culturas (COELHO et al., 2012). Na agricultura familiar, entretanto, as linhas laterais dos sistemas de irrigação são curtas e com isso o efeito negativo da qualidade dos emissores pode ser reduzido. O mercado atual apresenta diferentes tipos de emissores de baixo custo, tipo gotejador e tipo microaspersor. Esses emissores precisam ser avaliados para a condições de pequenas áreas, de forma a disponibilizar aos agricultores familiares indicações de emissores de baixo culto de melhor desempenho em campo. O trabalho teve como objetivo avaliar o desempenho de emissores de baixo custo por meio da variação de vazão e de pressão entre o primeiro e ultimo emissor da linha lateral.

\section{MATERIAL E MÉTODOS}

O experimento foi executado num campo experimental da Embrapa Mandioca e Fruticultura localizado no município de Cruz das Almas, Bahia, de latitude $12^{\circ} 48^{\prime} \mathrm{S}$, longitude $39^{\circ} 06^{\prime} \mathrm{W}$ e altitude de $225 \mathrm{~m}$, durante o período no período de novembro de 2011 a janeiro de 2013. O clima da região é classificado como úmido a subúmido e pluviosidade média anual de $1.143 \mathrm{~mm}$ (D’ANGIOLELLA et al., 1998). O solo da área experimental é classificado como Latossolo Amarelo distrófico, textura argilosa a moderada, ácido, com horizontes subsuperficiais coesos, oriundos de sedimentos da formação Capim Grosso (SOUZA \& SOUZA, 2001).

Foi instalado um sistema de irrigação com uma linha de derivação da qual saíram as linhas laterais de comprimento $20 \mathrm{~m}$. Emissores de água para irrigação localizada foram inseridos nas linhas laterais, sendo que cinco tipo de emissores (E1 - gotejador autocompensante de $4 \mathrm{Lh}^{-1}$; E2 - gotejador regulável tipo parafuso; E3 - microaspersor de orifício de 1,5 mm tipo difusor; E4 - gotejador regulável de oito saídas com abertura de uma volta no corpo do mesmo; E5 - gotejador regulável de oito saídas com abertura de duas voltas no corpo do mesmo. Os emissores foram inseridos ao longo da linha lateral a uma distancia entre eles de $1 \mathrm{~m}$, com três repetições, isto é, para cada emissor foram usadas três linhas laterais.

O delineamento experimental foi inteiramente casualizados, seguindo um esquema em parcelas subdivididas sendo para avaliação da variação da vazão $(5$ x 4), onde o tipo de emissor foi colocado na parcela (5) e a pressão de serviço (4) como subparcela. Para avaliação da pressão ao longo da linha lateral foram considerados os emissores E1, E2, E3 e E5 num esquema de parcelas subdivididas 4 x 4, sendo quatro tipos de emissores e quatro pressões no inicio da linha lateral para cada tipo de emissor. As pressões de serviço foram aplicadas no inicio da linha lateral sendo as mesmas 30, 60, 90 e $120 \mathrm{kPa}$, sendo que as leituras de pressão foram feitas com um manômetro de Bordon. As leituras de vazão foram feitas com um cronometro e uma proveta de $1000 \mathrm{ml}$ graduada. As variáveis analisadas foram a variação de vazão e a variação de pressão ao longo da linha lateral. Essa variação foi tomada pela vazão ou pressão no inicio da linha lateral e as mesmas variáveis no final da linha lateral, conforme a equação 


$$
\Delta P, V=\frac{(P, V)_{i}-(P, V)_{f}}{(P, V)_{i}} \cdot 100
$$

Em que $(\mathrm{P}, \mathrm{V})_{\mathrm{i}}-$ Pressão $(\mathrm{kPa}) /$ volume $(\mathrm{L})$ no inicio da linha lateral; $(\mathrm{P}, \mathrm{V})_{\mathrm{f}}-$ Pressão/volume no final da linha lateral; $\Delta \mathrm{P}, \mathrm{V}$ - variação de pressão, vazão (\%).

A analise de variância para avaliar o efeito do emissor e da pressão de serviço no inicio da linha lateral (fontes de variação) nas variáveis dependentes $\Delta \mathrm{P}, \mathrm{V}$ foi feita com uso do aplicativo SISVAR (FERREIRA, 2008).

\section{RESULTADOS E DISCUSSÃO}

A análise de variância detectou efeito do tipo de emissor, da pressão de serviço e da interação emissor x pressão de serviço no inicio da linha lateral na variação de vazão na linha lateral. O teste de Tukey não apresentou diferença significativa entre a variação de vazão média dos emissores, o que provavelmente se deveu aos elevados coeficientes de variação (Tabela 1). No caso do efeito da pressão, para as pressões de serviço de 60 a $120 \mathrm{kPa}$ houve uma redução na percentagem de variação de vazão com o aumento da pressão no inicio da linha lateral (Figura 1), sendo a maior variação para a menor pressão $(30 \mathrm{kPa})$. O gotejador autocompensante apresentou as menores variações de vazão para as pressões de 60 a $90 \mathrm{kPa}$, entretanto houve aumento da variação de vazão para a pressão no inicio da lateral de $120 \mathrm{kPa}$. O gotejador tipo párafuso foi o que apresentou as maiores variações de vazão independente das pressões de serviço, mesmo conservando a mesma posição do parafuso para todos os gotejadores (Tabela 2); foi o emissor de pior desempenho, sendo que a nível de produtor as variações tendem a ser maiores, uma vez que os mesmos não usam critérios de observação da posição do parafuso em cada gotejador. As variações de vazão para o emissor difusor fixo e para o emissor regulável, com uma volta de giro ou duas apresentaram variações de vazão próximas entre si.

Tabela 1. Comparação de médias (Teste de Tukey) de percentagem de variação de vazão entre diferentes tipos de emissores.

\begin{tabular}{lc}
\hline Tipo de emissor & \%variação de vazão \\
\hline Got. Regulável de 8 saídas 1 giro & 32,24 \\
Got. Regulável de 8 saídas 2 giros & 27,19 \\
Gotejador regulável tipo parafuso & 60,40 \\
Gotejador autocompensante & 25,89 \\
Microaspersor difusor & 25,39 \\
\hline
\end{tabular}

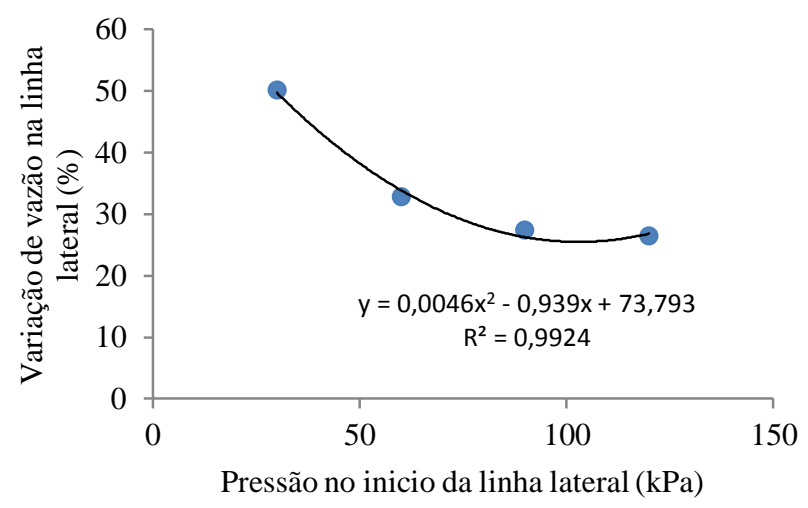

Figura 1. Percentagem de variação de vazão em função da pressão no inicio da linha lateral. 


\section{F. P. Santos et al.}

Tabela 2.Médias de percentagem de variação de vazão para diferentes pressões no inicio da linha lateral.

\begin{tabular}{ccc}
\hline $\begin{array}{c}\text { Pressão no } \\
\text { inicio da } \\
\text { linha lateral }\end{array}$ & $\begin{array}{c}\text { \% variação } \\
\text { vazão média do } \\
\text { gotejador } \\
\text { autocompensante }\end{array}$ & $\begin{array}{c}\text { \% variação } \\
\text { vazão média do } \\
\text { gotejador tipo } \\
\text { parafuso }\end{array}$ \\
\hline 30 & 77,77 & 62,69 \\
60 & 6,96 & 56,66 \\
90 & 3,68 & 69,47 \\
120 & 15,15 & 52,78 \\
\hline
\end{tabular}

O gotejador autocompensante apresentou percentagem de variação de vazão inferior a $10 \%$ (variação de vazão na linha lateral permitida em sistemas de irrigação, conforme Bernardo et al,. (2006) para as pressões no inicio da lateral de 60 e $90 \mathrm{kPa}$, entretanto todos os demais mostraram percentagens de variação da vazão superiores $19 \%$. Exceto o gotejador tipo parafuso, o de pior desempenho, os demais apresentaram variações de vazão próximas de $20 \%$ para pressões no inicio da lateral de 90 e 120 $\mathrm{kPa}$

A analise de variância referente a avaliação da percentagem de variação de pressão detectou efeito apenas da pressão no inicio da linha lateral e da interação emissor x pressão no inicio da linha lateral nessa variável dependente. $\mathrm{O}$ emissor em si não influenciou a variação de pressão na linha lateral devido as diferentes pressões de serviço no inicio da linha lateral (Tabela 3). A pressão no inicio da linha lateral influenciou a variação de pressão na linha lateral para todos os emissores (Figura 2). Os emissores tiveram o mesmo comportamento quanto a percentagem de variação de pressão na linha lateral em função da pressão no inicio da linha lateral, isto é, com um decréscimo dessa percentagem de variação com o aumento da pressão no inicio da linha lateral. O gotejador autocompensante a semelhança dos outros emissores apresentou maior percentagem de variação de pressão para a pressão de $30 \mathrm{kPa}$ no inicio da linha lateral. O microaspersor difusor apresentou para todas as pressões no inicio da linha lateral variações de pressão superiores aos demais emissores.

Tabela 3. Comparação de médias de percentagem de variação de pressão entre diferentes tipos de emissores.

\begin{tabular}{lc}
\hline Tipo de emissor & \%variação de pressão \\
\hline Got. Regulável de 8 saídas 1 giro & 24,97 \\
Gotejador regulável tipo parafuso & 24,99 \\
Gotejador autocompensante & 27,77 \\
Microaspersor difusor & 25,39 \\
\hline
\end{tabular}



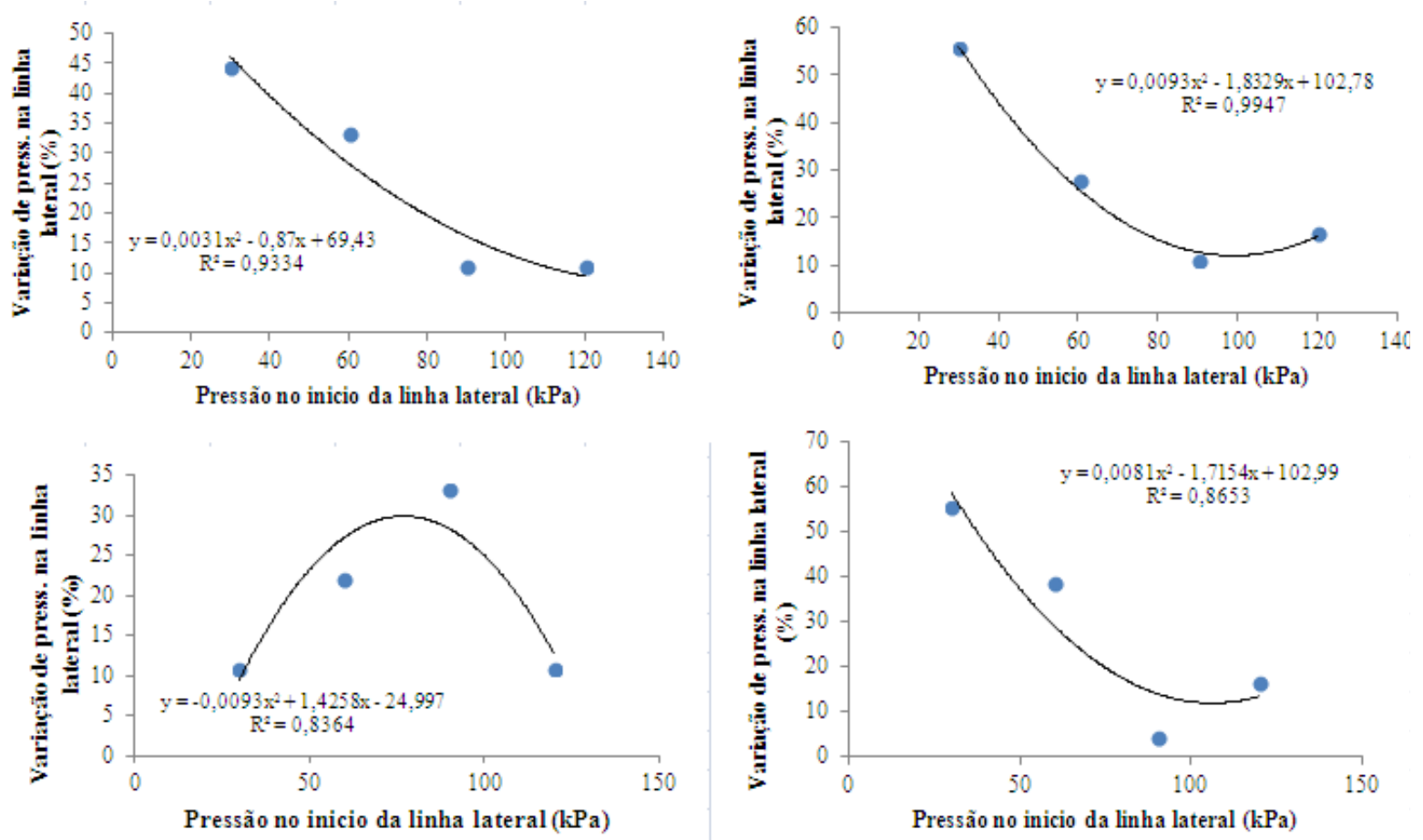

Figura 2. Percentagem de variação de pressão em função da pressão no inicio da linha lateral para (A) gotejador regulavel de oito saídas, (B) gotejador tipo parafuso, (C) gotejador autocompensante e (D) microaspersor difusor.

\section{CONCLUSÕES}

Ocorreu para a maioria dos emissores uma redução na percentagem de variação de vazão e de pressão com o aumento da pressão no inicio da linha lateral Exceto o gotejador tipo parafuso, o de pior desempenho, os demais apresentaram variações de vazão próximas de $20 \%$ para pressões no inicio da lateral de 90 e $120 \mathrm{kPa}$. O gotejador tipo parafuso é o de maior percentagem de variação de vazão e pressão, independente da pressão no inicio da lateral. $\mathrm{O}$ emissor em si não influenciou a variação de pressão na linha lateral devido as diferentes pressões de serviço no inicio da mesma.

\section{REFERÊNCIAS}

BERNARDO, S. Manual de Irrigação. 8. ${ }^{a}$ ed., Viçosa: UFV, 2006. 625p.

COELHO, E. F.; SILVA, T. S. M.; PARIZOTTO, I.; SILVA, A. J. P.; SANTOS, D. B. Sistemas de irrigação para agricultura familiar. Cruz das Almas: EMBRAPA-CNPMF, 2012. 7p. (EMBRAPA-CNPMF.Circular Técnica, 106

D’ANGiOlella, G. L. B.; CASTRO NETO, M. T.; COELHO, E. F. Tendências Climáticas Para Os Tabuleiros Costeiros da Região de Cruz das Almas In: CONGRESSO BASILEIRO DEENGENHARIA AGRÍCOLA, 27., 1998. Poços de Caldas. Anais... Lavras : SBEA, 1998. v. 1. p. 43-45.

FERREIRA, D.F. SISVAR: um programa para análises e ensino de estatística. Revista Symposium, Lavras, v. 6, p. 36-41, 2008.

FOOD and AGRICULTURE ORGANIZATION OF THE UNITAED NATIONS. New FAO publication aims to bring small-scale irrigation to farmers in sub-Saharan Africa. (http://www.fao.org/NEWS/1 997/970704-e.htm).

MAROUELLI, W. A.; SILVA, W. L. C. Irrigação. In: SILVA, J. B. C.; GIORDANO, L. B. (Ed.) Tomate para processamento industrial. Brasília: Embrapa Hortaliças, 2000. p. 60-71. 
F. P. Santos et al.

SOUZA, L. da S.; SOUZA, L. D. Caracterização físico-hídrica de solos da área do Centro Nacional de Pesquisa de Mandioca e Fruticultura Tropical. Cruz das Almas: EMBRAPA-CNPMF, 2001. 56p. (Boletim de Pesquisa, 20). 